\title{
Determinants of Patient Satisfaction in Hospital
}

\author{
E.Ratnam \\ Senior Lecturer, Department of Marketing, Faculty of management studies and commerce, university of Jaffna, \\ Sri Lanka
}

\begin{abstract}
Service quality is playing significance role in developing and building customer value and customer satisfaction in modern business world. In case of Sri Lankan government hospital, government has introduced several new attractive packages to enhance and also promote the patient satisfaction in different ways. Even though, success of implementation of the package is questionable. This study clearly investigates what types of factors impact of patient satisfaction in general hospital in Jaffna.
\end{abstract}

Keywords; brand, Brand awareness, patient satisfaction

\subsection{Background of the Study}

A measurement that obtains reports or ratings from patients about services received from an organization, hospital, physician or healthcare provider. The relationship between healthcare quality and patient satisfaction is a great source of debate. Some early researchers' depicted service quality perception is as a satisfaction outcome. It is argued that consumer satisfaction leads to an overall evaluation or attitude about service quality over time (Bitner et al., 1990; Parasuraman et al., 1988).

Later works, however, agree that service quality is a simpler, primarily a cognitive construct while satisfaction is a complex cognitive and affective construct. Satisfaction is a central construct that mediates the effect of service quality perception on behavioral intention and other outcomes (Bolton and Drew, 1991; Oliver, 1993; Shemwell et al., 1998; Brady and Robertson, 2001; Bigne et al., 2003). The importance of satisfaction is a key predictor of patients' intentional behaviors. In different countries and for different types of healthcare services, satisfied patients are more likely to return to the same provider and to recommend them to their families and friends (Bendall-Lyon and Powers, 2004; Otani and Harris, 2004; Zineldine, 2006; Taylor, 1994; Choi et al., 2005). Because satisfaction reflects positive judgments patients form about their healthcare service experiences, satisfied patients appear to have more trust in their providers, more confident about their dealings and more willing to recommend them to others. Patient satisfaction in a hospital is basically a state of mind of the patient. It is the ability of the hospital service to meet the expectations of the patient. Patient delight is all about exceeding the expectations of the patients to make them highly satisfied with the hospital. In hospital perspective, customer is any individual or institution who is an actual, potential or future user of the hospital and its various services. The customer from the hospital is very different from the regular customer, the difference being that they do not want to be a customer in the first place. The hospital customer is forced to be a customer because of their illness and parts with their money unhappily. Main objective of the study to investigate the kinds of factors determine the patient satisfaction in general hospital in Jaffna.

\subsection{Literature review}

Service marketers mean as service employee or staff. Service marketers usually are expected to be fast and efficiency at executing operational task .as well as courteous and helpful in dealing with the customers. In fact the front line employees are key input for delivering service excellence and competitive advantage. Behind, now a days most of today's successful service organizations stands a firm commitment to effective management of human resource including recruitment, selection, training, motivation, and retention of employees. Organizations that display this commitment is also characterized by a distinctive culture service leadership and role modeling by top management. (John E.G Basteson-1995). The front line employee is by definition at the "sharp end" of the service delivery system to execute the service effectively, the employee requires proper support from further back in the organization. (Rajendra Narjundra-2006). Donalal stated the following are the Service marketer's characters Reliability, Responsiveness, Competence, Courtesy, Credibility, and Empathy. Satisfaction is achieved through customer loyalty many organizations still claims that one of their strategic optional level customer satisfaction. Satisfaction creates through loyalty. customers can be satisfied \& still fact alternative suppliers, if apparent better deals suggest themselves more over the satisfaction is the end state in feeling accompanying the attainment by impulse of its objective.(Drever,1997). Other difference kinds of view of customer satisfaction (Keith Hunt 1991). Normative deficit definition: - Compares actual outcomes to those that are culturally acceptable. Equity definition: - Compares gains in a social exchange if the gains are in equal the loser is dissatisfied. Normative standard definition:-Expectation is based on what the consumer believes he/she should receive dissatisfaction occurs when the actual outcome is different from the standard expectation. Procedural fairness definition: - Satisfaction is a function of the consumer's belief that he/she was treated fairly. 
Customer satisfaction is generally described as the full meeting of one's expectations. Customer satisfaction is the feeling or attitude of a customer towards a product or service after it has been used. A review of the existing literature indicates that there can be potentially many antecedents of customer satisfaction, as the dimensions underlying satisfaction judgments are global rather than specific (Taylor and Baker, 1994; Patterson and Johnson, 1993; Rust and Oliver, 1994). The customer satisfaction literature has paid a great deal of attention to the confirmation paradigm, which concerns the comparison of product or service performance expectations and evaluations (Goode and Moutinho, 1995). The confirmation model treats satisfaction as a meeting of customer expectations (East, 1997; Oliver 1989) and is generally related to habitual usage of products (East, 1997). However, research on customer satisfaction has moved towards the disconfirmation paradigm which views satisfaction with products and brands as a result of two cognitive variables: pre purchase expectations and disconfirmation (Churchill and Surprenant, 1982; Peter and Olson, 1996).According to Peter and Olson (1996), "pre purchase expectations are beliefs about anticipated performance of the product; disconfirmation refers to the differences between pre purchase expectations and post-purchase perceptions". In an earlier study, Churchill and Surprenant (1982) reported that disconfirmation positively affected satisfaction. That is, when subjects perceived the product performing better than expected, they were more satisfied (Churchill and Surprenant, 1982). Further empirical research supports the notion that satisfaction is caused by expectations and requires considerable cognitive effort on the part of customers (Bearden and Teel, 1983; Moutinho and Goode, 1995; Cadotte et al., 1987).

CSRs can be differed from one another on a variety of dimensions and attributes. These are often collectively referred to in the Organizational Behavior/Human Re-sources literature as "knowledge, skills, and abilities" (KSAs), but can also include personality and other individual traits (Gatewood \& Field, 2001; Napoleon \& Gaimon, 2004). Some of these characteristics can influence the employee's customer support effectiveness. Hurley (1998) found that "superior service providers tend to be higher in extroversion and agreeableness". Similarly, Williams and Sanchez (1998) found that certain personality characteristics, including agreeableness and extroversion, predicted extra-role and role-prescribed service behavior. Lin, Chiu, and Hsieh (2001) empirically demonstrated that “. . . employees with different personality traits perform differently on customers' perceptions of service quality". In the virtual team's literature, there has been relatively little study of how KSAs influence team performance outside the team member characteristic of technical expertise and technology experience, suggesting that a broader net be cast in this regard (Martins et al., 2004).

Another literature examines the impact of various KSAs on related employee roles, such as sales (e.g., Saxe \& Weitz, 1982; Darian, Tucci, \& Wiman, 2001). Perhaps the most relevant in that stream is George (1991), which examined managers" perceptions of "customer-service behavior" (prosaically behavior directed at customers) of salespeople. That study measured how courteously, politely, and promptly the employee treated the customer; the employee's pleasantness and sincerity; listening attentiveness; and the salesperson's knowledge of the merchandise (among other things).

These and other studies and judgmental job performance data in general, typically rely on either selfassessments or supervisor assessments of a CSR's personality or other personal attributes (Gatewood \& Field, 2001). While information derived from manager- and employee-based assessments can be useful, that approach ignores the important contributions available through considering the customer's perceptions of the CSR (Frei \& McDaniel, 1998). An employee could be categorized in a way on a self-assessment instrument, but perceived quite differently by a supervisor, the customer, or when providing support over a technology-based medium (Gatewood \& Field, 2001; Alge, Gresham, Heneman, Fox, \& McMasters, 2002). This study hopes to add to our understanding of this issue by taking an approach different from the majority of the previous literature: It employs customer perceptions of CSR characteristics gathered almost immediately after a support experience.

Based on extensive conversations with managers overseeing customer sup-port operations at a leading, international Internet service provider (ISP), this re-search focused on six CSR characteristics often measured in industry surveys: Courtesy, Professionalism, Attentiveness, Knowledgeableness, Preparedness, and Thoroughness. These six were among the most commonly employed metrics (based on an internal survey of its major competitors) in the ISP industry, and were thought to be applicable to all commonly used customer support media at the time of the study.

Being courteous (i.e., well-mannered, polite, and considerate) to customers is such a basic and fundamental attribute that its presence in virtually any industry assessment of CSR characteristics is almost assumed. Courteous behavior is desired by service customers (Schneider, Parkington, \& Buxton, 1980; George, 1991; Verma, 2003) and reinforces the assurance dimensions of service quality (Parasuraman et al., 1985, 1988; Lin et al., 2001), or the rapport dimension of IS service quality (Kettinger \& Lee, 2005), by helping to establish a personal and trusting relationship between the customer and the service employee.

The benefits of employees' professional behavior and appearance are well-established in a variety of industrial and service environments (Gatewood \& Field, 2001; Nguyen \& Leblanc, 2002) and help to establish trust and confidence in the relationship. However, in situations where technology mediates the customer contact, 
the impact of this CSR characteristic is not clearly understood. There exists some empirical evidence to suggest that professionalism can be a performance differentiator, at least in commercial services (Chao \& Scheuing, 1994). Professionalism relates to the assurance and/or rapport dimensions of service quality in that it helps to engender a sense of confidence in the service provider's ability to perform adequately. While listening to the customer has long been considered a hallmark of world-class organizations (Prokesch, 1995), paying careful attention to individual customers during the contact episode can be a valuable CSR skill (George, 1991). Agrawal and Schmidt (2003) offer a preliminary theoretical foundation suggesting that service personnel which engage in attentive, perceptive, and responsive listening to customers can increase sales. Listening also engenders a sense of trust and relation-ship between the customer and the service provider, thereby helping to reinforce the concepts of responsiveness, assurance, and empathy vital to service quality (Parasuraman et al., 1988; Lin et al., 2001) and enabling both responsiveness and rapport (Kettinger \& Lee, 2005). It should be noted that listening, as used here, is taken broadly to encompass being attentive to a customer's statements about his issue, his psychological or emotional state, and so on, regardless of the medium employed (i.e., some online media, such as e-mail, have no, or a greatly reduced, aural/audio component, soit would not be appropriate to assess a strict interpretation of "listening" in those contexts.

Knowledgeable employees are better trained, up-to-date, and educated with respect to the details of their functions and their firms' products and services (George, 1991) and help ensure that problem-solving and other functional tasks are performed well. Knowledgeable sales reps have higher predicted performance (Darian et al., 2001). Anecdotal evidence for the value of knowledgeable service personnel has been found in face-toface settings (Higgins, 2003) and is demanded in online settings as well (Burke, 2002). Knowledgeable CSRs also may help reinforce the assurance/rapport dimension of service quality due to engendering confidence in their expertise (Parasuraman et al., 1988; Kettinger \& Lee, 2005).

A prepared CSR is more informed about the particular customer who is serving and, as a result, assumedly better able to address that customer's current need. Preparation for the task at hand is chief to excellence in customer service. The recent deluge of e-CRM (electronic customer relationship management) systems and solutions is primarily driven by the desire to get better (more accurate, up-to-date, detailed, etc.) information into the hands of personnel throughout the firm, primarily focusing on the marketing, sales, operations, and customer service functions (Rigby, Reichheld, \& Schefter, 2002). These information systems can greatly enhance the ability of the CSR to be prepared to perform his task (Berry \& Parasuraman, 1997). By having access to the right information and tools at the right time, the CSR is better equipped to render effective and relevant assistance to the customer. Being prepared enables the CSR to respond more capably and quickly to customer requests and helps engender a sense of assurance and empathy (Parasuraman et al., 1988), or rapport (Kettinger \& Lee, 2005).

This represents the desire and effort associated with ensuring that the customer's issue is addressed completely and systematically, and that the support task is fully executed. Asking probing questions about a customer's needs is a sign of positive customer service behavior (George, 1991). CSR thoroughness may also reinforce the service quality dimensions of reliability and assurance (Parasuraman et al., 1985, 1988). The service provider has a vested interest in the CSR being thorough as well, because it can reduce customer service expenses. A thorough CSR is more likely to address a customer's issue correctly and completely on the first contact, making that customer less likely to contact the firm again about the same issue. This has obvious operational and service quality benefits.

\subsection{Research Methods}

This study is carried out to validate the scale for patient satisfaction. For to get the relevant data the researcher has chosen general hospital in Jaffna.

After getting permission from the hospital authorities and inpatients the researcher collected the required information. The schedule has been prepared to validate the scale for patient satisfaction through the brand dimensions namely Brand preference which has 6 statements (Amira Elleuch, 2008), Brand image which has 5 statements (Park, et. al., 1986), Brand trust which has 4 statements (Hall, et.al., 2001), Brand association which has 16 statements (Gladden and Funk, 2002) comprises the brand value, brand attributes and brand affect and patient satisfaction which is measured with 3 statements (Ware and Hays, 1998). The statements are asked with 5 point likert's scale, where 1 stands for strongly disagree and 5 stands for agree. A sample of 365 respondents is selected for this study by using convenience sampling method. The schedule is filled by the researcher by contacting patients personally after then all the data are thoroughly checked and entered in to the SPSS 17 software package. 


\subsection{Research framework}

\section{Figure 1.1 research conceptual frameworks}

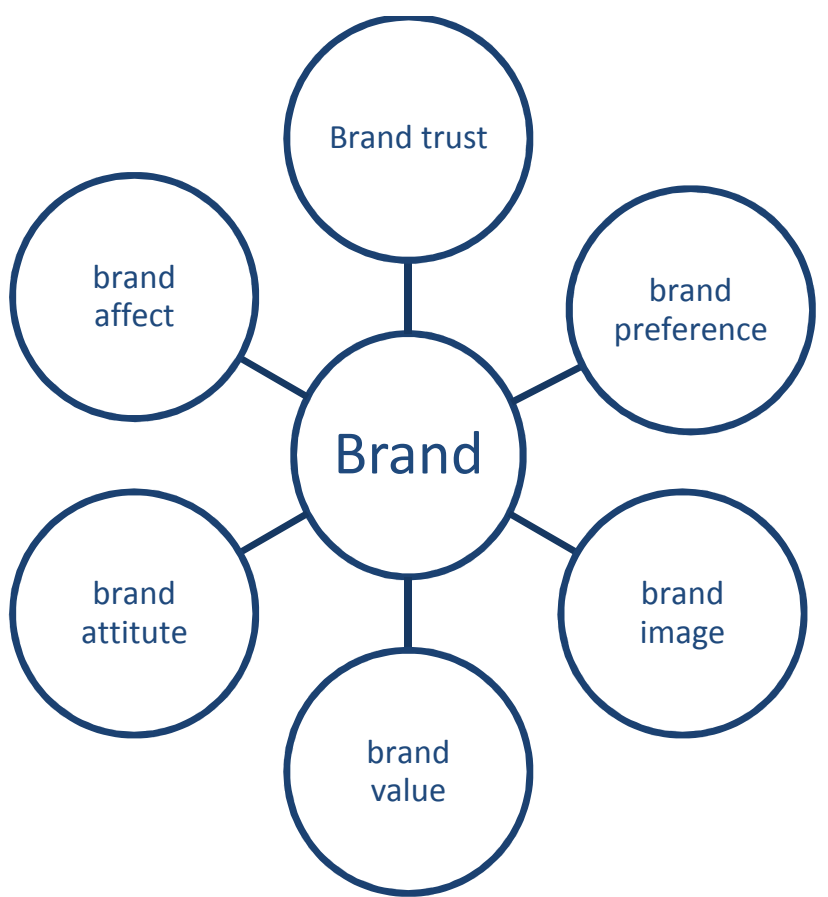

It is a fact that the branded hospital has a unique character in its services. Table-1 shows the patient opinion towards their brand preference. Brand preference is measured with six statements. The calculated mean value ranges between 4.21 and 4.60. This value indicates that the brand preference towards this hospital is high. The standard deviation value ranges from 0.72 to 0.83 . Brand preference assesses the respondents' opinion on the reasons for selecting this brand. Patients prefer this brand because of safety, professional appearance, promised services, error free treatment and it serves best interest of patients. These reasons are strongly agreed by the patients. It is observed that the brand is highly preferred by the patients because of its services.

Brand image of the hospital is measured with five statements. The respondents are asked to rate their opinion towards brand image of the hospital. Most of the respondents are highly rated that the hospital has the good brand image because the calculated mean value lies between 4.30 and 4.48. Patients believed that the hospital has reputation of excellence, widely popular for proper medical care and high percentage of recovery rate.

Trust is an especially relevant success factor in health-care communities. Brand trust is assessed by the patients' opinion. The respondents are asked to rate their opinion towards brand trust, which has four factors. The calculated mean value and standard deviation is ranged from 4.23 to 4.53 and 0.70 to 0.77 respectively. From the value, it is clearly identified that respondents are having high level of trust towards the hospital.

Brand association comprises the brand value, brand attributes and brand affect. Brand association is measured with sixteen factors in three dimensions as brand value, brand attributes and brand affect. Respondents are asked to rate their opinion towards brand association. Brand value has been assessed with four statements. Mean value ranges between 3.89 and 4.47 and standard deviation value ranges from 0.79 to 0.84 . This value indicates that the respondents perceive high level of brand value.

\subsection{Discussion and Managerial Implication}

Patients are preferred this brand because of safety, professional appearance, promised services, error free treatment and it serves the best interest of patients. These reasons are strongly agreed by the patients. It is found that the brand is highly preferred by the patients because of its services. And, the intensity level of reason for preferring this brand is significantly varied among the patients. The relationship among image perception, satisfaction, trust and loyalty determined the magnitude of their relative importance to a specific market by linking customer behaviour to the hospital loyalty. Marketer can emphasis the strength through develops a high quality of service and should train their employees to provide a friendly and attentive service to the customers all the time. Keeping in touch with customers and providing satisfaction and reinforcement to current and past customers between visits can enhance the customer loyalty. Appreciation of customer business, acting on their needs and regular communications can give the customer a reason to select this brand. These relationships will extend well beyond any single visit and will lead in the development of both satisfaction and loyalty that can 
contribute to repeat business and word-of-mouth advertisement.

\section{Reference}

Ahmad Jamal \& Mohammed Al Marri. (2007). Exploring the effect of self-image congruence and brand preference on satisfaction: the role of expertise. Journal of Marketing Management, 23(7), 613-629.

Amira Elleuch. (2008). Patient satisfaction in Japan. International journal of health care Quality assurance, 21(7), 692-705

Andreassen, T. W., \& Lindestad, B. (1998). Customer loyalty and complex services: the impact of corporate image on quality, customer satisfaction and loyalty for customers with varying degrees of service expertise. International Journal of Service Industry Management, 9(1), 7-23.

Bendall Lyon, D., \& Powers, T.L. (2004). The impact of structure and process attributes on satisfaction and behavioral intentions. The Journal of Services Marketing, 18(3), 114-21.

Bigne, E., Moliner, M.A., \& Sanchez, J. (2003). Perceived quality and satisfaction in multiservices organizations: the case of Spanish public services, The Journal of Services Marketing, 17(5), 420-443.

Bitner, k. (1996). Beyond customer satisfaction to customer loyalty, AMA management briefing, New York.

Bitner, M.J., Booms, B.H., \& Tetreault, M.S. (1990). The service encounter: diagnosing favorable and unfavorable incidents. Journal of Marketing, 54 (1), 71-82.

Bloemer, J. M. M., \& Kasper, H. D. P. (1995). The complex relationship between consumer satisfaction and brand loyalty. Journal of Economic Psychology, 16(2), 311-329.

Bloemer, J., \& Ruyter, K. (1998). On the Relationship between store image, store satisfaction, and store loyalty. European Journal of Marketing, 32, 499-513.

Bolton, R.N., \& Drew, J.H. (1991). A multistage model of customers assessments of service quality and value. Journal of Consumer Research, 17, 375-94.

Brady, M.K. \& Robertson, C.J. (2001). Searching for a consensus on the antecedent role of service quality and satisfaction: an exploratory cross-sectional study, Journal of Business Research, 51(1), 53-60.

Chaudhuri, A. \& Holbrook, M.B. (2001). The chain of effects from brand trust and brand affect to brand performance: the role of brand loyalty. Journal of Marketing, 65, 81-93.

Choi, K.S., Lee, H., Kim, C. \& Lee, S. (2005). The service quality dimensions and patient satisfaction relationships in South Korea: comparison across gender, age and types of service. The Journal of Services Marketing, 19(3), 140-149.

Colgate, M., Stewart, K., \& Kinsella, R. (1996). Customer defection: a study of the student market in Ireland. International Journal of Bank Marketing, 14(3), 23-29.

Erdem, T., Swait, J., \& Valenzuela, A. (2006). Brands as signals: a cross-country validation study. Journal of Marketing, 70, 34-49.

Fornell, C. (1992). A National Customer Satisfaction Barometer: The Swedish Experience. Journal of Marketing, 56(1), 6-21.

Gladden, J., \& Funk, D. (2002). Developing an understanding of brand associations in team sport: empirical evidence from consumers of professional sport. Journal of Sport Management, 16 (1), 54-81.

Gronroos, C. (1984). A Service Quality Model and its Marketing Implications. European Journal of Marketing, $18(4), 36-44$.

Gummesson, E., \& Gronroos, C. (1988). Quality of services: lessons from the product sector. In C. Suprenant (Ed.), Add Value to Your Service. Chicago, IL: American Marketing Association.

Hall, M. A., Dugan, E., Zheng, B., \& Mishra, A. K. (2001). Trust in Physicians and Medical Institutions: What Is It, Can It Be Measured, and Does It Matter. The Milbank Quarterly, 79(4), 613-639.

Hellier, P. K., Geursen, G. M., Carr, R. A., \& Rickard, J. A. (2003). Customer repurchase intention: A general structural equation model. European Journal of Marketing, 37(12), 1762-1800.

John, J. (1991). Improving quality through patient-provider communication. Journal of Health Care Marketing, 11(4), 51-60.

Kim, H.B., \& Kim, W. G. (2005). The Relationship between Brand Equity and Firms Performance in Luxury Hotels and Chain Restaurants. Tourism Management, 26(4), 549-560.

Kim, T., Kim, W. G., \& Kim, H. B. (2009). The effects of perceived justice on recovery satisfaction, trust, wordof-mouth, and revisit intention in upscale hotels. Tourism Management, 30, 51-62.

Lliyasu, Z., Abubakar, I.S., Abubakar,S., Lawan, U,N., \& Gajida, A.U. (2010). Patients' satisfaction with services obtained from Aminu Kano teaching hospital, Kano, Northern Nigeria. Nigerian Journal of clinical practice, 13(4), 371-378.

Mittal, B., \& Lassar, W.M. (1996). The role of personalization in service encounters. Journal of Retailing, 72 , 95-109.

Oliver, R. L. (1993). A conceptual model of service quality and service satisfaction: compatible goals, different concepts. Advances in Services Marketing and Management, 2, 65-85. 
Otani, K., \& Harris, L. (2004). Different integration process of patient satisfaction among 4 groups. Healthcare Management Review, 29(3), 188-195.

Park, C.W., Jaworski, B.J., \& Maclnnis, D.J. (1986). Strategic brand concept-image Management. Journal of Marketing, 50(4), 135-45.

Parasuraman, A., Zeithaml, E.V., \& Berry, L.L. (1988). SERVQUAL: a multiple items scale for measuring customers perception of service quality. Journal of Retailing, 64, 12-23.

Sivanenthira,S Sabina,D (2013) The impact of the service quality on customer satisfaction. South Asian academic research jurnals vol 4 190-198

Shemwell, D.J., Yavas, U., \& Bilgin, Z. (1998). Customer service provider relationships: an empirical test of service quality, satisfaction and relationship-oriented outcomes. International Journal of Service Industry Management, 9(2), 155-164.

Singh, J., Sirdeshmukh, D., \& Sabol, B. (2002). Consumer Trust, Value and Loyalty in Relational Exchanges. Journal of Marketing, 66, 15-34.

Sirdeshmukh, D., Singh, J., \& Sabol, B. (2002). Consumer trust, value and loyalty in relational exchanges. Journal of Marketing, 66, 15-37.

Soderlund, M. (1998). Customer satisfaction and its consequences on customer behavior revisited. International Journal of Service Industry Management, 9(2), 169-188.

Taylor, S.A. (1994). Distinguishing service quality from patient satisfaction in developing health care marketing strategy. Hospitals and Health Services Administration, 39(2), 237.

Terblanche, N. S. (2006). The relationship between customer satisfaction and loyalty: An application of the American Customer Satisfaction Index in the South African fast food industry. Management Dynamics, $15(2), 31-42$.

Thom, D. H., Kravitz, R. L., Bell, R. A., Krupat, E., \& Azari, R. (2002). Patient Trust in the Physician: Relationship to Patient Requests. Family Practice, 19(5), 476-483.

Thom, D. H., Hall, M. A., \& Pawlson, L. G. (2004). Measuring Patients' Trust in Physicians When Assessing Quality of Care. Quality of Care, 23(4), 124-132.

Ware, J. E., \& Hays, R. D. (1988). Methods for Measuring Patient Satisfaction with Specific Medical Encounters. Medicare Care, 26, 393-402.

Williams, B., Coyle, J. \& Healy, D. (1998). The meaning of patient satisfaction: an explanation of high reported levels. Social Science and Medicine, 47(9), 1351.

Zineldine, M. (2006). The quality of health care and patient satisfaction: an exploratory investigation of 5Q model at some Egyptian and Jordanian medical clinics. International Journal of Health Care Quality Assurance, 19(1), 60-92. 
The IISTE is a pioneer in the Open-Access hosting service and academic event management. The aim of the firm is Accelerating Global Knowledge Sharing.

More information about the firm can be found on the homepage:

http://www.iiste.org

\section{CALL FOR JOURNAL PAPERS}

There are more than 30 peer-reviewed academic journals hosted under the hosting platform.

Prospective authors of journals can find the submission instruction on the following page: http://www.iiste.org/journals/ All the journals articles are available online to the readers all over the world without financial, legal, or technical barriers other than those inseparable from gaining access to the internet itself. Paper version of the journals is also available upon request of readers and authors.

\section{MORE RESOURCES}

Book publication information: http://www.iiste.org/book/

Academic conference: http://www.iiste.org/conference/upcoming-conferences-call-for-paper/

\section{IISTE Knowledge Sharing Partners}

EBSCO, Index Copernicus, Ulrich's Periodicals Directory, JournalTOCS, PKP Open Archives Harvester, Bielefeld Academic Search Engine, Elektronische Zeitschriftenbibliothek EZB, Open J-Gate, OCLC WorldCat, Universe Digtial Library, NewJour, Google Scholar

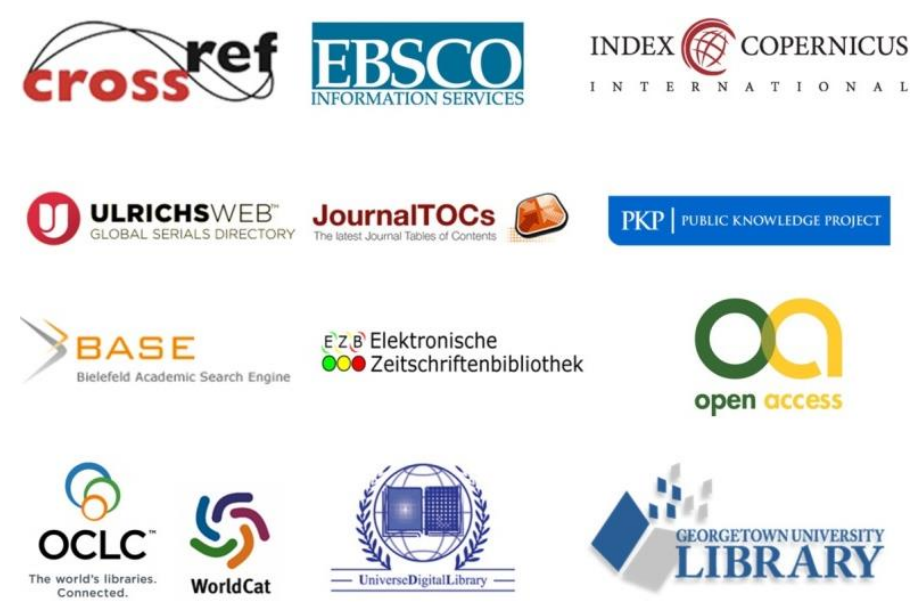

